\title{
ENCLOSING LEAVES FOR WATER POTENTIAL MEASUREMENT AND ITS EFFECT ON INTERPRETING SOIL-INDUCED WATER STRESS
}

\author{
WAYNE S. MEYER \\ CSIRO, Centre for Irrigation Research, PMB Griffith, NSW 2680, (Australia)
}

DON C. REICOSKY

USDA-ARS, North Central Soil Conservation Research Center Morris, MN 56267 (U.S.A.)

(Received August 1, 1984; revision accepted January 29, 1985)

\section{ABSTRACT}

Meyer, W.S. and Reicosky, D.C., 1985. Enclosing leaves for water potential measurement and its effect on interpreting soil-induced water stress. Agric. For. Meteorol., 35: $187-192$.

Accurate measurement of leaf xylem pressure potential $\left(\Psi_{x \text { exp }}\right)$ is needed to interpret plant water deficit effects in the field. Recent work has shown that values of $\Psi_{x}$ exp obtained from exposed leaves differ markedly from leaves enclosed immediately prior to excision. The present study was conducted to compare the effect of using values from exposed $\left(\Psi_{x \text { exp }}\right)$ and enclosed $\left(\Psi_{x \text { enc }}\right)$ leaves in the calculation of the soil-induced component of plant water stress. The pressure chamber technique was modified by using a sealing compound around the petiole and a laminated aluminium foil and polyethylene envelope to enclose a leaf beginning a few seconds prior to excision until the reading was completed one or two minutes later. The data showed that, as the air vapor pressure deficit (AVPD) increased, the absolute difference between $\Psi_{x \text { exp }}$ and $\Psi_{x}$ enc increased. When AVPD $=4 \mathrm{kPa}$, this difference was $0.8 \mathrm{MPa}$. The soil-induced component of the leaf pressure potential of cotton (Gossypium hirsutum L.) can be underestimated in absolute magnitude by up to $44 \%$ if $\Psi_{\mathrm{x}}$ exp values are used in the calculation. Removing this error by using $\Psi_{x}$ enc values subsequently improves both the discriminating ability of the plant water stress index proposed by Idso et al. (1982) and the accuracy of the estimate of the soil-induced component of leaf xylem pressure potential.

\section{INTRODUCTION}

The pressure chamber is a widely used field instrument for measuring xylem pressure potential of leaves $\left(\Psi_{x \exp }\right)$. A number of precautions necessary to obtain correct readings were highlighted by Ritchie and Hinckley (1975). However, the work of Turner and Long (1980) clearly shows that very large errors can result if water loss from leaves is not prevented from the time of excision until the measurement is made. The magnitude of this error is both plant and environment dependent. Although the diurnal change in this error has been shown for a number of species (Turner and Long, 1980) the relationship to atmospheric evaporative demand, as measured by the air vapor pressure deficit (AVPD), has not been shown. This note examines this relationship for cotton and the effect that the error has on the sensitivity of the relationship between the plant water stress index 
(a)

(b)

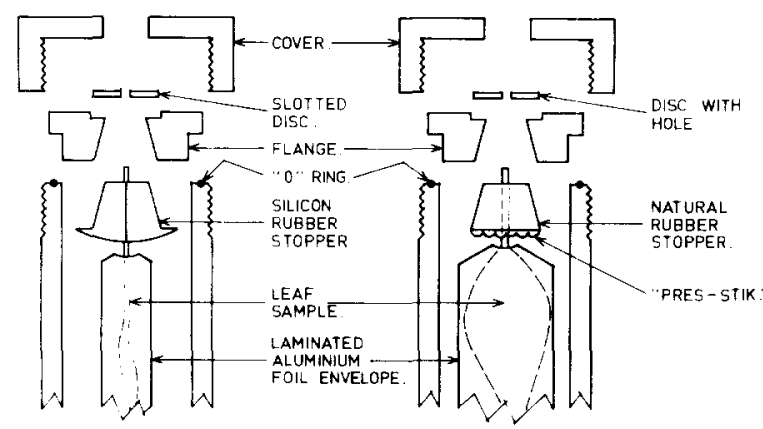

Fig. 1. Plan of the sealing arrangement for (a) grass-type leaves (adapted from Blum et al., 1973) and (b) leaves with petioles in the pressure chamber.

derived from canopy temperature measurements and the soil-induced plant water potential as shown by Idso et al. (1982).

\section{TERMINOLOGY}

In recent years, water potentials have been measured on leaves which have been subjected to various pretreatments. For clarity, the following terms are defined: (1) Exposed leaf xylem pressure potential ( $\Psi_{\mathrm{x} \text { exp }}$ ) where little or no effort is made to prevent water loss from the leaf. (2) Covered leaf xylem pressure potential $\left(\Psi_{\mathbf{x} \text { cov }}\right)$ where leaves are enclosed for some time prior to excision in order to establish a leaf water potential which is in equilibrium with that in the stem at the junction of the xylem elements (Meyer and Ritchie, 1980). (3) Enclosed leaf xylem pressure potential $\left(\Psi_{\mathbf{x} \text { enc }}\right)$ where leaves are enclosed immediately prior to excision.

\section{MATERIALS AND METHODS}

\section{Pressure chamber}

The design of Blum et al. (1973) (Fig. 1) was found to be most satisfactory for measurements on leaf strips of wheat (Triticum aestivum L.), sorghum (Sorghum bicolor (L.) Moench) and corn (Zea mays L.). The system was not satisfactory for leaves with irregularly shaped petioles because excessive leakage occurred around the gland seal. The use of the rubber compression gland as originally proposed by Scholander et al. (1965) was found to be cumbersome and required a special flange fitting that resulted in stem constriction and occasional breakage. The problems of leakage and the need to use another flange were overcome simply by using a natural rubber stopper with a hole to hold the petiole. A small amount of Bostik Pres-Stik or Blu-Tack or equivalent was placed on top of the rubber stopper. The Pres-Stik adhered to the roughened surface of the rubber stopper but did not adhere strongly to plant tissue. Petioles were inserted into the 
stopper with the aid of a corkborer of appropriate size used as a conduit. It was not necessary for the petiole to be tightly held by the rubber stopper provided that the Pres-Stik was pressed around the petiole to form a seal. This technique has been used successfully with leaves of orange (Citrus sinensis (L.) Osbeck), soybean (Glycine max (L.) Merr.), sunflower (Helianthus annuus) and cotton (Gossypium hirsutum L.) with chamber pressures up to $3 \mathrm{MPa}$. The depth of the rubber stopper was reduced when orange leaves with short petioles were sampled.

\section{Enclosing the leaves}

Various methods of enclosing leaves have been reported ranging from aluminium foil (Meyer and Ritchie, 1980) to plastic (Turner and Long, 1980 ) to plastic cling film (Leach et al., 1982). Aluminium foil is punctured by "pin-holes", the number being inversely related to foil thickness and is not entirely satisfactory for preventing water loss, as shown by Turner (1981). The non-rigidity of plastic films makes them difficult to use in windy field situations. A suitable compromise is to make envelopes or sheaths from aluminium foil ( $30 \mu \mathrm{m}$ thick) laminated to low density polyethylene $(25 \mu \mathrm{m}$ thick $)$. This material has the advantages of being impermeable, easy to handle and shape and is re-usable. The edges of the envelope can easily be heat sealed (with an electric soldering iron) while the aluminium foil excludes light from the leaf.

\section{Field measurements}

Measurements of xylem pressure potential were made on well-watered cotton plants grown in the field during the summer of $1982 / 83$ at the Centre for Irrigation Research, Griffith, NSW, Australia. Readings were made near solar noon except for several which were made during the early morning when the AVPD was low. An aspirated psychrometer held about $1 \mathrm{~m}$ above the crop canopy was used to determine AVPD. Young, fully expanded, fully sunlit leaves were inserted into laminated envelopes and the bulk air expelled by gently flattening the envelope. The leaf lamina was then sealed in the envelope by folding over the opening immediately prior to cutting the petiole. The enclosed leaves were taken to the on-site pressure chamber in a second larger reflective plastic bag as a further precaution against water loss. The leaves remained enclosed in the envelope during the entire procedure. Leaves used to measure the exposed leaf xylem pressure potential $\left(\Psi_{\mathrm{x} \text { exp }}\right)$ were cut and immediately conveyed to the chamber without being enclosed or covered at any time.

\section{RESULTS AND DISCUSSION}

The time required from excision to a determination of $\Psi_{\mathrm{x} \text { exp }}$ or $\Psi_{\mathrm{x} \text { enc }}$ was $101 \pm 22 \mathrm{~s}$. During this time, water loss from exposed leaves was sufficient to cause a difference between $\Psi_{\mathrm{x} \text { enc }}$ and $\Psi_{\mathrm{x} \exp }$ of up to 0.8 MPa. The 
Air vapor pressure deficit ( $\mathrm{kPa}$ )

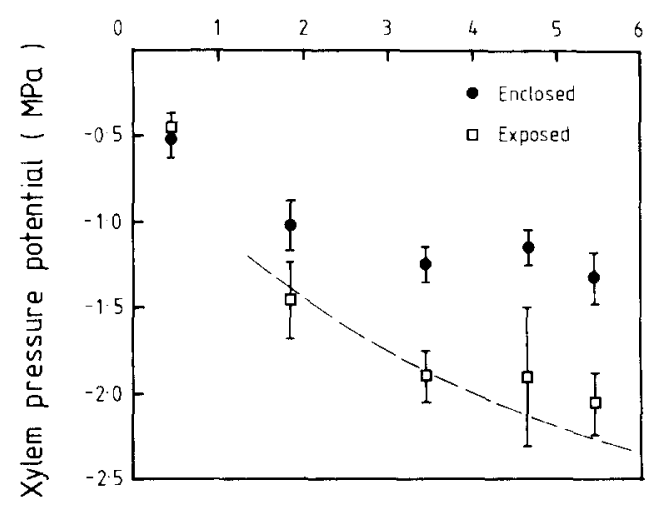

Fig. 2. Relation between the air vapor pressure deficit and xylem pressure potential for enclosed and exposed cotton leaves from well-watered plants. Bars are standard deviations derived from 16 to 32 readings at each point. The dashed line is the eye-fit line given by Idso et al., (1982) for their cotton data.

magnitude of this change is comparable to those reported elsewhere (Turner and Long, 1980; Leach et al., 1982). Figure 2 clearly shows that the magnitude of the difference is a function of AVPD. The points for $\Psi_{\mathrm{x}} \exp$ are a good fit of those given by Idso et al. (1982) although the general eye-fit dashed line drawn by these authors fail to follow either their data or ours when AVPD is greater than $4 \mathrm{kPa}$.

One effect of obtaining $\Psi_{\mathrm{x} \text { enc }}$ is that the absolute magnitude of the pressure potential values is decreased. This decrease is also accompanied by a reduction in the variability of the measurements. For example, the mean standard deviation for $\Psi_{x \text { enc }}$ at AVPD $>1.5 \mathrm{kPa}$ was $\pm 0.126 \mathrm{MPa}$ compared to $\pm 0.246 \mathrm{MPa}$ for $\Psi_{\mathrm{x}} \exp$. These values represent coefficients of variation (Snedecor and Cochran, 1967, p. 62) of 10.7 and $13.4 \%$ respectively. Another effect of obtaining $\Psi_{\mathrm{x} \text { enc }}$ values is that the different species responses reported by Idso et al. (1982) will be more clearly demonstrated. Turner and Long (1980) observed that the difference between $\Psi_{\mathrm{x} \text { exp }}$ and $\Psi_{\mathrm{x} \text { enc }}$ was affected by the water retention characteristics of a species. Using $\Psi_{\mathrm{x} \text { enc }}$ values eliminates the error previously induced by these different water retention characteristics effective after excision of the leaf for $\Psi_{\mathrm{x} \text { exp }}$ determination.

Idso et al. (1982) use a relationship similar to that shown in Fig. 2 to derive values attributable to the soil-induced component of the total plant water potential in situations other than where the crop is well watered. This measure of the effect of a drying soil is then related to the canopytemperature derived index of plant water stress. The ultimate aim is to use the index as a measure of the soil water status as integrated by the crop. If, however, the relationship is derived from measurements of $\Psi_{\mathrm{x}}$ enc it will not be confounded by variable atmospheric demand for evaporation from 
an excised leaf and will therefore be more discriminating, as can be shown from the following example.

For well-watered plants, the measured $\Psi_{\mathrm{x} \exp }$ is mainly attributable to the evaporative demand of the atmosphere and

$\Psi_{\mathrm{x} \exp }^{\mathrm{w}}=\Psi_{\mathrm{x} \text { enc }}^{\mathrm{w}}+\Psi_{\Delta}^{\mathrm{w}}$

where the superscript $w$ denotes well-watered plants and $\Psi_{\Delta}^{\mathrm{w}}$ is the change in xylem pressure potential induced by the loss of water after excision. For example, from Fig. 2 at an AVPD of $4 \mathrm{kPa}, \Psi_{\mathrm{x} \text { exp }}^{\mathrm{w}} \simeq-2.0 \mathrm{MPa}, \Psi_{\mathrm{x} \text { enc }}^{\mathrm{w}} \simeq$ $-1.2 \mathrm{MPa}$ and $\Psi_{\Delta}^{\mathrm{w}} \simeq-0.8 \mathrm{MPa}$.

When plants are in a drying soil a component of the measured $\Psi_{\mathrm{x} \text { exp }}$ will be induced by the insufficient supply of water through the soil. In this case

$\Psi_{\mathrm{x} \exp }^{\mathrm{d}}=\Psi_{\mathrm{x} \text { enc }}^{\mathrm{d}}+\Psi_{\Delta}^{\mathrm{d}}$

where the superscript $d$ represents plants in a drying soil, and $\Psi_{x \exp }^{d}$ and $\Psi_{\mathrm{x} \text { enc }}^{\mathrm{d}}$ are the exposed and enclosed xylem pressure potentials and $\Psi_{\Delta}^{\mathrm{d}}$ is the change in potential induced by the loss of water after excision.

The soil-induced component of the measured leaf pressure potential $\left(\Psi_{\mathrm{g}}\right)$ is assessed as

$\Psi_{\mathrm{g}}=\Psi_{\mathrm{x} \exp }^{\mathrm{d}}-\Psi_{\mathrm{x} \exp }^{\mathrm{w}}$

Substitution of eqs. 1 and 2 into the right hand side of eq. 3 gives:

$\Psi_{\mathrm{g}}=\left(\Psi_{\mathrm{x} \exp }^{\mathrm{d}}+\Psi_{\Delta}^{\mathrm{d}}\right)-\left(\Psi_{\mathrm{x} \exp }^{\mathrm{w}}+\Psi_{\Delta}^{\mathrm{w}}\right)$

If $\Psi_{\Delta}^{\mathrm{d}}=\Psi_{\Delta}^{\mathrm{w}}$ then use of $\Psi_{\mathrm{x} \text { enc }}$ as opposed to $\Psi_{\mathrm{x} \text { exp }}$ values makes no difference to the value of $\Psi_{\mathrm{g}}$. However Turner and Long (1980, Fig. 3a) show for cotton that as $\Psi_{\mathrm{x} \text { enc }}$ decreases below $-2.2 \mathrm{MPa}$ due to soil drying $\Psi_{\Delta}^{\mathrm{d}}$ decreases, so that when $\Psi_{x \text { enc }}^{d}=-3 \mathrm{MPa}, \Psi_{\Delta}^{\mathrm{d}}=0$ i.e. $\Psi_{\mathrm{x} \text { exp }}^{\mathrm{d}}=-3 \mathrm{MPa}$.

Let us now assess the value of $\Psi_{\mathrm{g}}$ in a field of cotton plants were $\Psi_{\mathrm{x}}^{\mathrm{d}} \exp$ is measured at $-3.0 \mathrm{MPa}$. A plot of these same plants watered a day before the measurements is assumed (from field experience) to give a value of $\Psi_{\mathrm{x} \text { exp }}^{\mathrm{w}}=-2.0 \mathrm{MPa}$. Using eq. $3, \Psi_{\mathrm{g}}=-1.0 \mathrm{MPa}$. If however, $\Psi_{\mathrm{g}}$ is assessed using enclosed leaf xylem pressure potentials i.e.

$\Psi_{\mathrm{g}}=\Psi_{\mathrm{x} \text { enc }}^{\mathrm{d}}-\Psi_{\mathrm{x} \text { enc }}^{\mathrm{w}}$

then a value of $-1.8 \mathrm{MPa}$ results since $\Psi_{\mathrm{x} \exp }^{\mathrm{d}}=-3.0 \mathrm{MPa}, \Psi_{\mathrm{x} \text { enc }}^{\mathrm{d}}=-3.0$ $\mathrm{MPa}$ (Turner and Long, 1980) and when $\Psi_{\mathrm{x} \exp }^{\mathrm{w}}=-2.0 \mathrm{MPa}, \Psi_{\mathrm{x} \text { enc }}^{\mathrm{w}}=$ $-1.2 \mathrm{MPa}$ (Fig. 2 with AVPD $=4 \mathrm{kPa}$ ). Thus, there is considerable difference between the two estimates of $\Psi_{\mathrm{g}}$; an absolute underestimate of $44 \%$ if values of $\Psi_{x \text { enc }}$ are not used. This example is likely to be the extreme case but it serves to illustrate that the error in estimating $\Psi_{\mathrm{g}}$ can be large.

Idso et al. (1982) use the relationship between $\Psi_{x}^{\mathrm{w}} \exp$ and AVPD to develop a further relationship between $\Psi_{\mathrm{g}}$ and a plant water stress index (PWSI). If, however, values of $\Psi_{\mathrm{x} \text { enc }}^{\mathrm{w}}$ are used instead of $\Psi_{\mathrm{x} \text { exp }}^{\mathrm{w}}$, the linear relation between $\Psi_{\mathrm{g}}$ and PWSI given in their Fig. 5 has an increased slope. 
Thus, for a change of 0.1 in the PWSI, the estimated change in $\Psi_{\mathrm{g}}$ will be $-0.23 \mathrm{MPa}$ if the relationship is based on $\Psi_{\mathrm{x} \text {; }}^{\mathrm{w}}$ measurements, but -0.40 $\mathrm{MPa}$ using $\Psi_{\mathrm{x} \text { enc }}^{\mathrm{w}}$ measurements. This increased sensitivity combined with the reduced variability of $\Psi_{\mathrm{x} \text { enc }}$ measurements will enhance the discriminating ability of the PWSI.

The present evidence, together with that which has already been published, clearly indicates that enclosing leaves immediately prior to and during pressure chamber measurements should become standard procedure.

\section{ACKNOWLEDGEMENTS}

The authors are grateful to Mr. G. Mann and Mr. R. Sides for help with collecting the field data and to Mr. G.C. Green and Dr. S. Moreshet for discussions during adaptation of the pressure chamber technique.

\section{REFERENCES}

Blum, A., Sullivan, C.Y. and Eastin, J.D. 1973. On the pressure chamber technique for estimating leaf water potential in sorghum. Agron. J., 65: 337-338.

Idso, S.B., Reginato, R.J. and Farah, S.M., 1982. Soil- and atmosphere-induced plant water stress in cotton as inferred from foliage temperatures. Water Resour. Res., 18: $1143-1148$.

Leach, J.E., Woodhead, T. and Day, W., 1982. Bias in pressure chamber measurements of leaf water potential. Agric. Meteorol., $7: 257-263$.

Meyer, W.S. and Ritchie, J.T., 1980. Resistance to water flow in the sorghum plant. Plant Physiol., 65: 33-39.

Ritchie, G.A. and Hinckley, T.M., 1975. The pressure chamber as an instrument for ecological research. Adv. Ecol. Res., 9: 165-254.

Scholander, P.F., Hammel, H.T., Bradstreet, E.D. and Hemmingsen, E.A., 1965, Sap pressure in vascular plants. Science, $148: 339-346$.

Snedecor, G.W., and Cochran, W.G., 1967. Statistical methods. 6th edn., Iowa State Univ. Press, Ames, IA.

Turner, N.C., 1981. Correction of flow resistances of plants measured from covered and exposed leaves. Plant Physiol., 68: 1090-1092.

Turner, N.C. and Long, M.J., 1980. Errors arising from rapid water loss in the measurement of leaf water potential by the pressure chamber technique. Aust. J. Plant Physiol., 7: 527-537. 